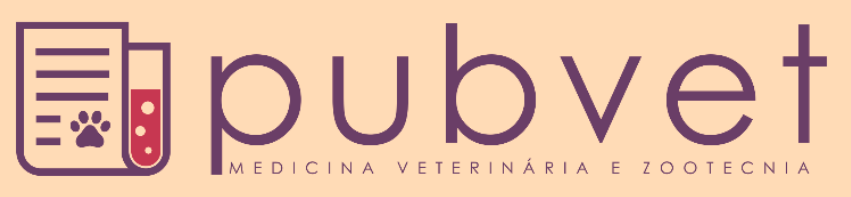

https://doi.org/10.31533/pubvet.v15n01a734.1-7

\title{
Erliquiose monocitotrópica canina: Revisão
}

\section{Catherina Stival ${ }^{1 \oplus}$, Edna Aparecida da Silva Suzuki ${ }^{10}$, Isabella Gomes Oliveira ${ }^{1 \oplus}$, Victoria Faria do Carmo ${ }^{1 *}$}

${ }^{1}$ Acadêmica de Medicina Veterinária do Centro Universitário de Goiânia. Goiânia-GO, Brasil.

*Autor para correspondência, E-mail: victoriafcvet@gmail.com

Resumo. A erliquiose é uma enfermidade que acomete os cães, podendo ocorrer também em humanos, causada pela Ehrlichia spp, sendo a mais diagnosticada a Ehrlichia canis, que é uma bactéria Gram-negativa, transmitida pelo carrapato, principalmente o Rhipicephalus sanguineus. É uma pandemia, que tem seus sinais clínicos inespecíficos, e é capaz de acometer vários órgãos, sendo necessário para diagnóstico o exame físico, exame hematológico e sorológico, encontrando de forma recorrente anemia normocítica normocrômica, leucopenia e trombocitopenia.

Palavras-chave: Carrapato, erliquiose, hemoparasitose

\section{Canine monocyotropic ehrlichiosis: Review}

Abstract. Ehrlichiosis is a disease that affects dogs and can also occur in humans, caused by Ehrlichia spp., the most diagnosed being Ehrlichia canis, which is a Gram-negative bacterium, transmitted by ticks, mainly Rhipicephalus sanguineous. It is a pandemic, which has its nonspecific clinical signs, and is capable of affecting several organs, being necessary for diagnosis of the physical examination, hematological and serological examination, finding normochromic normocytic anemia, leukopenia and thrombocytopenia regularly.

Keywords: Tick, ehrlichiosis, hemoparasites

\section{Ehrlichiosis monociotrópica canina: Revisión}

Resumen. La ehrlichiosis es una enfermedad que afecta a los perros y también puede presentarse en humanos, causada por Ehrlichia spp., la más diagnosticada es Ehrlichia canis, que es una bacteria gramnegativa, transmitida por garrapatas, principalmente Rhipicephalus sanguineus. Es una pandemia, que tiene signos clínicos inespecíficos, y es capaz de afectar varios órganos, siendo necesario para el diagnóstico el examen físico, el examen hematológico y serológico, encontrando anemia normocrómica normocítica, leucopenia y trombocitopenia de manera recurrente.

Palabras clave: Garrapata, ehrlichiosis, hemoparasitosis

\section{Introdução}

A erliquiose canina é causado por uma bactéria, com forma de cocobacilos, Gram-negativa, é uma riquétsia do gênero Ehrlichia, família Anaplasmataceae, ordem Rickettsiales, gênero Ehrlichia spp., espécie E. canis, E. chaffeensis, E. ewingii, E. muris e E. ruminantium. Sua replicação ocorre por divisão binaria (Aguiar et al., 2007; Nelson \& Couto, 2015), sendo que a E. canis é a principal espécies que atinge os canídeos (Benigno et al., 2011).

Devido ao carrapato (Rhipicephalus sanguineus), que é o principal veiculador da doença e é disseminado por todo território brasileiro, a incidência de casos dessa patologia vem aumentando de 
forma significativa (Benigno et al., 2011). A E. canis tem como hospedeiro secundário os vertebrados, acometendo inclusivamente o homem, se caracterizando como uma zoonose; os cães e todas suas raças, porém os filhotes tem o maior comprometimento e se enquadram nos casos mais severos (Moraes et al., 2004; Souza et al., 2012).

A transmissão ocorre para o Rhipicephalus sanguineus ao se alimentar de um animal portador da doença na fase aguda, contraindo a riquétsia, em sua forma larval ou adulta (Dagnone et al., 2003). Não ocorre transmissão transovariana (Nelson \& Couto, 2015). O agente permanece vivo dentro do vetor por até 5 meses, se replicando nas glândulas salivares e hemócitos, podendo transmitir essa infecção em até 155 dias após serem infectados, que ocorre no momento em que o carrapato faz o repasto sanguíneo em um outro cão sadio (Dagnone et al., 2003), dessa forma, a riquétsia será inoculada junto a saliva, ou através do procedimento de transfusão sanguínea (Tilley et al., 2008).

A erliquiose é uma doença que causa lesões em vários órgãos, ou seja, multissistêmica, possui um período de incubação de 08 a 20 dias, apresentando 03 (três) fases com apresentação laboratorial semelhante, o que dificulta a sua diferenciação, sendo elas: fase aguda, subclínica ou assintomática e crônica (Harrus et al., 1997).

O diagnóstico é feito por diversos métodos, mas principalmente pela contagem de plaquetas devido às alterações que a bactéria é capaz de causar, como trombocitopenia (Jain \& Gupta, 1997; Mendonça et al., 2005), através do esfregaço sanguíneo, onde será possível a visualização direta do patógeno, PCR (Alves et al., 2005; Nakaghi et al., 2008) e por técnicas como IFI (imunofluorescência indireta e o Elisa que irá pesquisar a presença de anticorpos para E. canis no soro (Brandão, 2010).

No tratamento, o fármaco de eleição, principalmente na fase aguda da doença, é a doxiciclina em dose de $10 \mathrm{mg} / \mathrm{kg}$ por via oral, de $24 \mathrm{em} 24$ horas (uma vez ao dia), por um período de 28 dias (Baneth \& Hartmann, 2006).

Cães com erliquiose aguda tendem a ter um bom prognóstico, pois os sintomas desaparecem em poucos dias após o início do tratamento. Já em casos crônicos é de reservado a desfavorável, devido a supressão da medula óssea que fará com que o animal não tenha uma boa resposta ao tratamento, podendo demorar meses para a resolução clínica (Tilley et al., 2008).

\section{Etiologia e epidemiologia}

A erliquiose monocitotrópica canina (EMC) é causada pela Ehrlichia canis, pertencente ao gênero Ehrlichia, ordem Rickettsiale, família Anaplasmataceae (Taylor et al., 2017). A E. canis é uma bactéria Gram-negativa cocoide, pequena, intracelular obrigatória, dentro de monócitos e macrófagos, e formam agrupamentos chamados mórulas (Nelson \& Couto, 2015). A E. canis é considerada um organismo pequeno, que mede de 0,2 a $0,4 \mu \mathrm{m}$ de diâmetro. O organismo se cora em azul com o corante de Romanowsky, vermelho-claro com o corante de Macchiavello e castanho-escuro com coloração de prata (Taylor et al., 2017).

Há cinco espécies do gênero Ehrlichia reconhecidas atualmente: E.canis, E. ewingii, E. chaffeensis, E. ruminantium e E. muris (Dumler et al., 2001), sendo a E. canis, a mais comum em cães e que apresenta manifestações clínicas mais graves. Ela é mantida no ambiente através do artrópode vetor que é o carrapato marrom do cão, Rhipicephalus sanguineus (Nelson \& Couto, 2015). Os carrapatos adquirem a E. canis na forma de larvas ou ninfas, ao se alimentarem em cães com riquetsiemia e são capazes de transmitir a infecção durante pelo menos 155 dias aos cães suscetíveis, parecendo mais grave em cães da raça Doberman, Pinscher e Pastor-alemão (Greene, 2017; Tilley et al., 2008). O patógeno tem a capacidade de hibernar no carrapato e isso possibilita que ele infeste e infecte cães suscetíveis na primavera seguinte. A doença pode ocorrer durante o ano inteiro, porém ocorre com maior frequência durante a estação quente, quando o número de carrapatos vetores são abundantes (Greene, 2017).

A espécie Rickettsia canis foi identificada pela primeira vez em cães por Donetein e Lestoquard na Argélia, em 1935, sendo renomeada como Erlichia canis por Mashkovsky em 1945. No Brasil, a doença foi relatada pela primeira vez em 1973, na cidade de Belo Horizonte (Buhles et al., 1974). Porém, essa doença só recebeu uma atenção notória quando uma grande quantidade de cães militares norteamericanos, a maioria da raça Pastor-alemão, morreram dessa doença na Guerra do Vietnã. No final da 
década de 1980, a E. canis esteve em evidência pelas suspeitas errôneas que as riquétsias pudessem infectar seres humanos, mas em 1991, foi constatado que a causa da erliquiose monocitotrópica humana era devido a uma nova espécie do gênero Ehrlichia, a E. chaffeensis (Greene, 2017). Atualmente, é possível constatar que a distribuição da E. canis é mundial (Greene, 2017; Taylor et al., 2017).

\section{Transmissão}

A transmissão ocorre durante o repasto sanguíneo, o momento em que o carrapato (Rhipicephalus sanguineus), conhecido como carrapato marrom, parasita um animal infectado. Esse carrapato, irá contrair a riquétsia, tornando-se o portador da doença e ao parasitar outro cão, irá transmitir a riquétsia junto da saliva no momento do repasto sanguíneo, dessa forma, irá infectar o cão (Souza et al., 2012). O carrapato é encontrado principalmente em regiões tropicais e temperadas (Souza et al., 2012). Outro meio considerado, é através da transfusão sanguínea, um sangue não previamente testado, pode estar infectado pela E.canis (Dagnone et al., 2003).

\section{Sinais clínicos}

A Ehrlichiose é uma doença multissistêmica (Greene, 2017), que acomete quaisquer cães, sem idade de predileção, sendo machos e fêmeas igualmente afetados (Taylor et al., 2017). A virulência pode ser alterada devido às diferentes cepas que existem de E. canis, e a forma grave da erliquiose acontece em cães com imunossupressão (Nelson \& Couto, 2015). É importante destacar que, assim como o E. canis é transmitido pelo carrapato $R$. sanguineus, outros microrganismos também podem ser transmitidos por ele, como a Babesia canis vogeli e Hepatozoon canis, podendo desenvolver coinfecção e complicando a doença de base (Greene, 2017).

As manifestações clínicas são inespecíficas, mas a doença pode-se apresentar em 3 fases, que podem levar a morte do animal caso não tratada: fase aguda, subclínica e crônica (Monteiro, 2011). Os achados hematológicos são leucopenia, trombocitopenia e ligeira anemia (Birchard \& Sherding, 2008).

$\mathrm{Na}$ fase aguda o período de incubação são de 8 a 20 dias e pode se estender por 2 a 4 semanas. Os sinais clínicos mais recorrentes da fase aguda envolvem hipertermia $\left(39,5-41,5^{\circ} \mathrm{C}\right)$, (Monteiro, 2007) depressão, letargia, anorexia, perda de peso, taquipneia, mas são sinais inespecíficos da doença. Os sinais específicos são linfadenomegalia, esplenomegalia (acontecem devido a replicação dos leucócitos nesses órgãos), petéquias e equimoses na pele (resultados da combinação de trombocitopenia moderada e vasculite), e membranas mucosas (Souza et al., 2012; Taylor et al., 2017). Sinais como febre, vômito, secreção oculonasal serosa ou purulenta e dificuldade respiratória são sinais pouco frequentes nessa doença (Taylor et al., 2017). Ao se fazer esfregaço sanguíneo é possível visualizar a presença de mórulas do parasita (Souza et al., 2012).

$\mathrm{Na}$ fase sub-clínica o agente continua no animal depois de um falso alarme de que o animal se recuperou da fase aguda, então os sinais são brandos ou tão discretos que o tutor não vai perceber e essa fase pode se estender por meses ou até anos (Birchard \& Sherding, 2008). Alterações hematológicas não são evidenciadas com frequência, mas é nessa fase que ocorre a elevação de anticorpos (Garcia et al., 2018).

Na fase crônica, os sinais apresentados são parecidos com o da fase aguda, mas se apresenta mais grave e assume um aspecto de doença autoimune (Monteiro, 2007; Taylor et al., 2017). O animal vai apresentar palidez de mucosas devido a pancitopenia, emaciação e edema periférico, pode ter febre, hepatomegalia, esplenomegalia e linfadenopatia (que são consequências da estimulação imune progressiva); nos machos pode ter edema de escroto e nas fêmeas não castradas o período de estro pode se prolongar, infertilidade pode acontecer assim como abortos e morte neonatal (Taylor et al., 2017). Os achados hematológicos englobam monocitose, linfocitose e trombocitopenia persistente juntamente com a anemia arregenerativa (Rotondano, 2010).

Quando a E. canis entra nos órgãos de predileção (baço, fígado e linfonodos), as células de defesa conhecida como monócitos entram em ação, se ligando as células do endotélio, iniciando a vasculite. A anemia observada nos exames hematológicos corresponde de uma hipoplasia de medula que ocorre na fase crônica (Stiles, 2000). Outras alterações que a Erliquiose canina pode trazer são alterações oculares como na cor, uveíte, hifema, hemorragia subretinal, deslocamento de retina e cegueira (Barcellos et al., 
2011; Greene, 2017). Já os sinais neurológicos incluem convulsões, meningoencefalite, ataxia, disfunção neuromotora e vestibular central ou periférica e hiperestesia localizada ou generalizada (Donizete, 2016).

\section{Diagnóstico}

O diagnóstico da infecção por E. canis se baseia na anamnese, atentando-se principalmente ao histórico, como residência ou viagens a regiões endêmicas, sendo o histórico por infestação de carrapatos um dos mais importantes para a suspeita clínica, associado com o diagnóstico laboratorial (Taylor et al., 2017). No exame hematológico, é possível identificar algumas alterações que são predominantes durante a infecção por E. canis, sendo elas: trombocitopenia, anemia normocítica, normocrômica, eosinopenia, linfopenia e desvio nuclear de neutrófilos para esquerda (Barcellos et al., 2011).

Uma forma de diagnóstico considerada confirmatória é a identificação de mórulas em um esfregaço sanguíneo proveniente do sangue periférico, na ponta da orelha (Birchard \& Sherding, 2008). É possível identificar a presença dessas estruturas cerca de 12 a 15 dias após a infecção no sangue periférico e na medula óssea, respectivamente; entretanto, a ausência de parasitas no esfregaço sanguíneo não exclui a possibilidade de infecção (Lasta, 2011). Nestes casos, é indispensável que sejam realizados exames complementares sorológicos, como a técnica de imunofluorescência indireta ou o PCR, sendo o último uma técnica sensível e específica que permite a identificação da espécie (Nelson \& Couto, 2015).

Para a realização de alguns diagnósticos diferenciais deve-se levar em consideração a infecção por Babesia, com o intuito de eliminar as chances da sua existência, através de um exame hematopatológico. A leishmaniose também deve ser considerada pela presença em comum de epistaxe, que ocorre em casos crônicos de erliquiose, a diferenciação é feita através de uma punção de medula óssea ou gânglios (Silva et al., 2013).

\section{Tratamento}

O tratamento para erliquiose consiste no uso de antibióticos, principalmente os da classe das tetraciclinas. A doxiciclina é a mais utilizada, devido a sua boa absorção intestinal e alcançar alta concentração celular, o que é bom, pois a Ehrlichia é uma bactéria intracelular. Não existe um consenso que determine a duração do tratamento, mas alguns autores recomendam que seja administrado por 21 - 28 dias na dose de $10 \mathrm{mg} / \mathrm{kg}$, com intervalos de 12 ou 24 horas (Jericó et al., 2015; Moraillon et al., 2013).

Outros fármacos que podem ser utilizados como segunda opção são o cloranfenicol (15 a $20 \mathrm{mg} / \mathrm{kg}$, a cada 8 h, por via intravenosa, subcutânea ou oral) e o dipropionato de imidocarb (duas aplicações, com intervalo de 15 dias, na dose de $5 \mathrm{mg} / \mathrm{kg}$, por via subcutânea). Mas deve se ter alguns cuidados na administração dos mesmos. O cloranfenicol deve ser administrado com cuidado em animais com aplasia de medula óssea, e o imidocarb pode apresentar alguns efeitos colaterais, como salivação, secreção nasal serosa, diarreia e dispneia e se for necessário deve ser aplicado atropina (Jericó et al., 2015).

Além do tratamento com antibióticos, deve ser realizado também o tratamento sintomático, que inclui reposição hidroeletrolítica, complexos vitamínicos, antieméticos e se necessário transfusão sanguínea (número de glóbulos vermelhos inferior a 2.000.000/ $\mathrm{mm}^{3}$ ) (Jericó et al., 2015; Moraillon et al., 2013).

Em casos de risco de morte ou trombocitopenia grave, o uso de glicocorticosteróides pode ser indicado. A prednisolona é a mais recomendada, utilizando-se doses de $2 \mathrm{mg} / \mathrm{kg}$ por 2 a 7 dias. Imunomoduladores como o levamisol também podem ser administrados para estimular a imunidade do animal, sendo a dose utilizada de 0,5 a $2 \mathrm{mg} / \mathrm{kg}$, por via subcutânea. E em casos crônicos, por causa de processos hemorrágicos, deve ser feita a suplementação de ferro $(100$ a $300 \mathrm{mg}$, a cada 24 h, durante 3 a 5 meses), (Jericó et al., 2015).

Mesmo com o fim do tratamento e a cura, o animal deve ser monitorado, pois ainda é sensível a novas infecções e é importante avaliar os parâmetros hematológicos, pois títulos de anticorpos elevados constantemente é um indicativo de persistência da infecção ou que ele teve uma nova reinfecção. Para 
fazer esse monitoramento recomenda-se a realização de PCR de amostras do baço e medula óssea devido sua alta sensibilidade (Jericó et al., 2015; Moraillon et al., 2013).

\section{Prognóstico}

O prognóstico depende da resposta do animal ao tratamento e a fase da doença na qual ele se encontra, se for agudo, o prognóstico é considerado favorável e acompanhando da terapia apropriada; na fase subclínica, é considerado de favorável à reservado, pelo cão se apresentar assintomático, não irá receber tratamento, podendo evoluir para a fase crônica da doença; a fase crônica, é considerada desfavorável em casos de comprometimento da medula óssea, hipoplásica, e se houver hemorragia é considerada fatal (Tilley et al., 2008).

\section{Prevenção}

Não existe nenhuma vacina disponível para prevenção da E. canis, por isso recomenda-se o uso de antiparasitários no animal e no ambiente em que ele vive, mas principalmente nas épocas mais críticas e em animais que ficam expostos aos carrapatos (Greene, 2017; Lorenz \& Kornegay, 2006). Fazendo o uso dos antiparasitários corretamente ocorre a quebra do ciclo evolutivo do carrapato, que tem todo seu estágio evolutivo no animal, e $E$. canis e outros agentes patogênicos não completarão seu ciclo, nem infectará os cães.

Os medicamentos mais comuns para prevenção do carrapato são amitraz, fibronil e piretrinas (Greene, 2017; Taylor et al., 2017). Para o controle dos animais portadores é recomendado o tratamento terapêutico com tetraciclinas já que ela funciona muito bem como fármaco profilático tanto para infecção inicial quanto para casos de reinfecção, administrada na dose de $6,6 \mathrm{mg} / \mathrm{kg} / \mathrm{dia}$ por via oral (VO) (Ramsey \& Tennant, 2010).

\section{Conclusão}

A erliquiose monocitotrópica canina (EMC) é uma doença que apresenta relatos de muitos anos e tem grande ocorrência na clínica de pequenos, porém apresenta poucos estudos em volta dela. Seus sinais clínicos são inespecíficos o que dificulta o diagnóstico, sendo necessário a realização de exames complementares. Além disso é uma enfermidade que requer um tratamento longo e que se não for feito corretamente pode levar a morte do animal.

\section{Referências}

Aguiar, D. M., Saito, T. B., Hagiwara, M. K., Machado, R. Z., \& Labruna, M. B. (2007). Diagnóstico sorológico de erliquiose canina com antígeno brasileiro de Ehrlichia canis. Ciência Rural, 37(3), 796-802. https://doi.org/10.1590/S0103-84782007000300030

Alves, L. M., Linhares, G. F. C., Chaves, N. S. T., Monteiro, L. C., \& Linhares, D. C. L. (2005). Avaliação de iniciadores e protocolo para o diagnóstico da pancitopenia tropical canina por PCR. Ciência Animal Brasileira, 6(1), 49-54.

Baneth, G., \& Hartmann, K. (2006). Infectious diseases of the dog and cat. In C E Greene (Ed.), Hepatozzon canis Infection (3ed ed., Vol. 1, p. 698). Elsevier Health Sciences.

Barcellos, H. H. A., Melatti, L., Linck, C. M., Gavioli, F. B., Quadros, A. M., Palma, M. D., Casagrande, G., Oro, G., Valle, S. F., \& Motta, A. C. (2011). Aspectos clínicos e laboratoriais em cães com babesiose crônica. In Congresso Brasileiro de Medicina Veterinária.

Benigno, R. N. M., Rodrigues, B. R. F., \& Serra-Freire, N. M. (2011). Avaliação das infecções por Babesia e Ehrlichia em cães e das infecções humanas por carrapatos oriundos desses cães no município de Campinas, estado de São Paulo. Revista Brasileira de Medicina Veterinária, 33(4), 238-245.

Birchard, S. J., \& Sherding, R. G. (2008). Manual Saunders: clínica de pequenos animais. In Ed. Roca (Vol. 3).

Brandão, L. (2010). Hemoparasitoses em cães e gatos: aspectos clínicos e laboratoriais. MERIAL Saúde Animal. 
Buhles, W. C., Huxsoll, D. L., \& Ristic, M. (1974). Tropical Canine Pancytopenia: Clinical, Hematologic, and Serologic Response of Dogs to Ehrlichia canis Infection, Tetracycline Therapy, and Challenge Inoculation. Journal of Infectious Diseases, 130(4), 357-367. https://doi.org/10.1093/infdis/130.4.357

Dagnone, A. S., De Morais, H. S. A., Vidotto, M. C., Jojima, F. S., \& Vidotto, O. (2003). Ehrlichiosis in anemic, thrombocytopenic, or tick-infested dogs from a hospital population in South Brazil. Veterinary Parasitology, 117(4), 285-290. https://doi.org/https://doi.org/10.1016/j.vetpar.2003.10.001.

Donizete, J. C. (2016). Ocorrência de erliquiose em cães atendidos em clínica médico veterinária da cidade de Arcos-MG. Trabalho de Conclusão de Curso (Graduação de Medicina Veterinária)-Centro Universitário de Formiga - UNIFOR-MG, Formiga, 2016.

Dumler, J. S., Barbet, A. F., Bekker, C. P., Dasch, G. A., Palmer, G. H., Ray, S. C., Rikihisa, Y., \& Rurangirwa, F. R. (2001). Reorganization of genera in the families Rickettsiaceae and Anaplasmataceae in the order Rickettsiales: unification of some species of Ehrlichia with Anaplasma, Cowdria with Ehrlichia and Ehrlichia with Neorickettsia, descriptions of six new species combi. International Journal of Systematic and Evolutionary Microbiology, 51(6), 2145-2165. https://doi.org/10.1099/00207713-51-6-2145

Garcia, D. A., Martins, K. P., Cortezi, A. M., \& Gomes, D. E. (2018). Erliquiose e Anaplasmose CaninaRevisão de Literatura. Revista Científica, 1(1).

Greene, Craig E. (2017). Doenças infecciosas em cães e gatos (Roca; $4^{\mathrm{a}}$ e). Grupo Gen-Editora Roca Ltda.

Harrus, S., Kass, P. H., Klement, E., \& Waner, T. (1997). Canine monocytic ehrlichiosis: a retrospective study of 100 cases, and an epidemiological investigation of prognostic indicators for the disease. Veterinary Record, 141(14), 360-363.

Jain, V. K., \& Gupta, S. L. (1997). Successful treatment of canine ehrlichiosis with doxycycline: A case report. Indian Veterinary Journal, 74(3), 252-253.

Jericó, M. M., Kogika, M. M., \& Andrade Neto, J. P. (2015). Tratado de medicina interna de cães e gatos. Guanabara Koogan.

Lasta, C. S. (2011). Fatores de risco, parâmetros hematológicos, detecção molecular e sorológica de Ehrlichia canis e Anaplasma plantys em cães de porto Alegre/RS-Brasil. Fatores de Risco, parâmetros hematológicos e detecção molecular e sorológica de Ehrlichia canis e Anaplasma platys em cães de Porto Alegre/RS - Brasil.

Lorenz, M. D., \& Kornegay, J. N. (2006). Neurologia veterinária. Manole.

Mendonça, C. S., Mundim, A. V., Costa, A. S., \& Moro, T. V. (2005). Erliquiose canina: Alterações hematológicas em cães domésticos naturalmente infectados. Bioscience Journal, 21(1), 167-174.

Monteiro, D. S. G. (2007). Parasitologia Veterinária-UFSM. Universidade Federal de Santa Maria. Rio Grande Do Sul. Livro Didático $2^{a}$ Edição.

Monteiro, S. G. (2011). Parasitologia na medicina veterinária (Vol. 1). Roca.

Moraes, H. A., Almosny, N. R. P., \& Labarthe, N. (2004). Diretrizes gerais para diagnóstico e manejo de cães infectados por Ehrlichia spp. Clínica Veterinária, 9(48), 28-30.

Moraillon, R., Legeay, Y., Boussarie, D., \& Sénécat, O. (2013). Manual Elsevier de Veterinária: Diagnóstico e tratamento de Cães, gatos e animais exóticos (7th ed.). Elsevier.

Nakaghi, A. C. H., Machado, R. Z., Costa, M. T., André, M. R., \& Baldani, C. D. (2008). Canine ehrlichiosis: clinical, hematological, serological and molecular aspects. Ciência Rural, 38(3), 766770.

Nelson, R., \& Couto, C. G. (2015). Medicina interna de pequenos animais. Elsevier Brasil.

Ramsey, I. K., \& Tennant, J. R. B. (2010). Manual de doenças infecciosas em cães e gatos. São Paulo: Roca.

Rotondano, E. F. (2010). Avaliação de diferentes fontes de DNA para a realização de nested PCR no diagnóstico de erliquiose canina. Dissertação (Mestrado). Programa de Pós-Graduação em Ciências Biológicas, Universidade Federal de Pernambuco.

Silva, M. V. M., Fernandes, R. A., Nogueira, J. L., \& Ambrósio, C. E. (2013). Erliquiose canina: revisão 
de literatura. Arquivos de Ciências Veterinárias e Zoologia Da UNIPAR, 14(2), 139-143.

Souza, D. M. B., Coleto, Z. F., Souza, A. F., Silva, S. V, Andrade, J. K., \& Gimenez, G. C. (2012). Erliquiose transmitida aos cães pelo carrapato marrom (Rhipicephalus sanguineus). Ciência Veterinária Nos Trópicos, 15, 21-31.

Stiles, J. (2000). Canine rickettsial infections. Veterinary Clinics: Small Animal Practice, 30(5), 11351149.

Taylor, M. A., Coop, R. L., \& Wall, R. L. (2017). Parasitologia Veterinária. Guanabara Koogan.

Tilley, L. P., Smith, J. R., \& Francis, W. K. (2008). Consulta veterinária em 5 minutos: Espécies canina e felina. Editora Manole.

Histórico do artigo:

Recebido: 26 de junho, 2020.

Licenciamento: Este artigo é publicado na modalidade Acesso Aberto sob a licença Creative Aprovado: 31 de julho, 2020.

Commons Atribuição 4.0 (CC-BY 4.0), a qual permite uso irrestrito, distribuição, reprodução em

Disponível online: 25 de novembro, 2020. qualquer meio, desde que $\mathrm{o}$ autor $\mathrm{e}$ a fonte sejam devidamente creditados. 